Article

\title{
Establishment of a Faba Bean Banker Plant System with Predator Orius strigicollis for the Control of Thrips Dendrothrips minowai on Tea Plants under Laboratory Conditions
}

\author{
Chang-Rong Zhang ${ }^{1}$, Mei Liu ${ }^{1,2}$, Fei-Xue Ban ${ }^{1, *}$, Xiao-Li Shang ${ }^{3, *}$, Shao-Lan Liu ${ }^{1}$, Ting-Ting Mao ${ }^{1}$, \\ Xing-Yuan Zhang ${ }^{1}$ and Jun-Rui Zhi ${ }^{2}$
}

1 Institute of Plant Protection, Guizhou Academy of Agricultural Sciences, Guiyang 550006, China; zhangchangrong2006@163.com (C.-R.Z.); liumei721122@163.com (M.L.); lan605605@163.com (S.-L.L.); maotingting2922@163.com (T.-T.M.); stirm_zhangxy@163.com (X.-Y.Z.)

2 Institute of Entomology, Guizhou Provincial Key Laboratory for Agricultural Pest Management of the Mountainous Region, Guizhou University, Guiyang 550025, China; zhijunrui@126.com

3 Key Laboratory of Biology and Medical Engineering, School of Biology and Engineering, Guizhou Medical University, Guiyang 550025, China

* Correspondence: feixueban@163.com (F.-X.B.); shangx12013@163.com (X.-L.S.); Tel.: +86-851-17816872203 (F.-X.B.); +86-851-19985506170 (X.-L.S.)

Citation: Zhang, C.-R.; Liu, M.; Ban, F.-X.; Shang, X.-L.; Liu, S.-L.; Mao, T.-T.; Zhang, X.-Y.; Zhi, J.-R. Establishment of a Faba Bean Banker Plant System with Predator Orius strigicollis for the Control of Thrips Dendrothrips minowai on Tea Plants under Laboratory Conditions. Insects 2021, 12, 397. https://doi.org/ $10.3390 /$ insects 12050397

Academic Editors: Antonio Masetti and Giovanni Burgio

Received: 8 March 2021

Accepted: 27 April 2021

Published: 29 April 2021

Publisher's Note: MDPI stays neutral with regard to jurisdictional claims in published maps and institutional affiliations.

Copyright: (c) 2021 by the authors Licensee MDPI, Basel, Switzerland. This article is an open access article distributed under the terms and conditions of the Creative Commons Attribution (CC BY) license (https:// creativecommons.org/licenses/by/ $4.0 /)$
Simple Summary: The banker plant system may provide an effective and economical method for long-term suppression of insect pests. We developed a non-crop banker plant system aiming to improve the control of stick tea thrips Dendrothrips minowai in tea plantations. In this system, we used the polyphagous predator Orius strigicollis (Poppius) as the biocontrol agent, the black bean aphid Aphis fabae (Scopoli) as an alternative food, and the faba bean Vicia faba L. as the banker plant to support the predator in controlling pest thrips. Laboratory tests revealed that the control efficacy of the banker plant system was higher than that of directly releasing $O$. strigicollis. These results indicate that this banker plant system may be used in the field to provide a more effective and economical way to control pest thrips in tea plantations compared with the direct release of $O$. strigicollis.

Abstract: The stick tea thrip Dendrothrips minowai (Priesner) (Thysanoptera: Thripidae) is a destructive pest in tea plantations in south and southwest China. To control this pest, a non-crop banker plant system was developed using a polyphagous predator Orius strigicollis (Poppius) (Heteroptera: Anthocoridae) with the black bean aphid Aphis fabae (Scopoli) (Hemiptera: Aphididae) as an alternative prey and the faba bean Vicia faba as the banker plant to support the predator in targeting the pest. The fitness of $A$. fabae on tea plants and faba bean was evaluated to determine its host specificity. Moreover, the control efficacy of the banker plant system on D. minowai on tea plants was tested in the laboratory and compared with that of direct release of $O$. strigicollis. The experiments showed that faba bean was an excellent non-crop host for $A$. fabae because, while the aphid population increased quickly on faba bean, it could only survive for up to 9 days on tea plants. Compared with direct release of $O$. strigicollis, lower densities of pest were observed when introducing the banker plant system. Our results indicate that this banker plant system has the potential to be implemented in the field to improve the control of the pest thrips.

Keywords: alternative prey; biological control; Aphis fabae; control efficacy; Camellia sinensis

\section{Introduction}

Tea is a traditional Chinese beverage, and the cultivated area of tea plant Camellia sinensis (L.) O. Kuntze (Theaceae) in China reached 45.75 ha in 2020. Tea plants are prone to infestations of pests and diseases, which lead to losses in harvest yield and quality. The 
stick tea thrip Dendrothrips minowai Priesner (Thysanoptera: Thripidae) is one of the main pests that causes serious damage in tea plantations. This species is mainly distributed in south and southwest China, especially Guizhou Province [1,2]. Adults and nymphs of D. minowai damage the tender leaves using rasping-sucking mouth parts, causing leaf abscission, wrinkling, and growth retardation, which seriously impact tea quality and yield [3]. According to previous studies, control methods for D. minowai primarily include timely weeding, pruning, and application of pesticides (e.g., azadirachtin, chlorfenapyr, and bifenthrin) [3,4]. Due to pesticide resistance and residue problems, increasing attention has been focused on integrated pest management based on biological control. Recently, biological control of D. minowai by natural enemies, such as the predatory mite Amblyseius cucumeris (Oudemans) (Acari: Phytoseiidae) and the ladybeetle Harmonia axyridis (Pallas) (Coleoptera: Coccinellidae), has been reported [4]. However, many other natural enemies and their potential applications have not been studied.

Flower bugs of the Orius genus (Hemiptera: Anthocoridae) are among the most effective predators of thrips, whiteflies, mites, and other small pests. To date, many Orius species have been successfully released as predators to control pests, for example, O. niger (Wolff) and O. laevigatus (Fieber) against Frankliniella occidentalis (Pergande) in Turkey [5], and O. minutus (L.) and O. niger (Wolf.) against Odontothrips loti (Hal.) in Romania [6]. In addition, flower bugs such as O. laevigatus, O. insidiosus, and O. majusculus have been commercialized in the Americas and European countries [7-9]. Among Orius spp., O. strigicollis (Poppius), which was also known as O. similis (Zheng) [10], has been found to effectively control various pests, especially thrips and aphids [11-13]. It is also a potential biological control agent of D. minowai.

Although many studies have shown that releasing natural enemies can effectively control pests (e.g., [14-16]), the requirement for large numbers of natural enemies and high cost have limited application. In addition, poor establishment and persistence of natural enemies significantly influence the sustainability of control efficacy. It is imperative to find methods to overcome these problems. One possible solution is the "banker plant system" (also called the open-rearing system), which is a natural enemy rearing and release system typically consisting of banker plant, alternative food, and beneficial insects (predators or parasitoids) [17]. Banker plants grow together with the primary crop and provide alternative food such as pollen or non-pest herbivores to promote the survival and reproduction of natural enemies. Therefore, natural enemies can be established on the banker plant and then target specific pests without the need to repeatedly release these natural enemies. As the banker plant system can offset the drawbacks of augmentative and conservation biological control, it has been applied in pest control in greenhouses or fields in several countries [17-20]. Banker plant systems with flower bugs as beneficial insects have also been developed, for example, ornamental pepper (Capsicum annuиm) as a banker plant providing pollen as alternative food for support of $O$. insidiosus for the control of F. occidentalis in ornamental grass [21,22], and Calendula officinalis as a banker plant supplying extrafloral nectaries as an alternative food for the support of O. sauteri for the control of F. occidentalis in tomato [23]. However, use of the flower bug-banker plant system for the control of tea pests is less common.

Faba bean (Vicia faba L.) is a host plant of Aphis fabae, which is a suitable aphid prey for flower bugs [24,25]. Although A. fabae is polyphagous, it prefers legumes, and we speculate that it may not infest tea plants. Furthermore, faba bean can provide some benefits to flower bugs, such as nectar, pollen, shelter, and egg-laying sites [26]. Therefore, faba bean was considered as a potential banker plant to maintain O. strigicollis through providing A. fabae as an alternative food.

The goal of this study was to develop a novel O. strigicollis-based banker plant system for the control of D. minowai. Specifically, we evaluated (a) the fitness of $A$. fabae on tea plants to determine if $A$. fabae is a non-pest for tea plants and (b) the use of the banker plant system consisting of $O$. strigicollis-faba bean- $A$. fabae for the control of $D$. minowai 
on tea plants. In addition, we compared the efficacy of this system with that of the direct O. strigicollis release.

\section{Materials and Methods}

\subsection{Insects and Plants}

Colonies of $O$. strigicollis were established from specimens collected from corn fields at Guizhou Academy of Agricultural Sciences, Guizhou, China. The species identity was determined using the method of Zhang et al. [27]. O. strigicollis were reared with Frankliniella occidentalis adults and Sitotroga cerealella eggs as prey for 4-6 generations. The D. minowai were collected from a tea plantation of the Guizhou Academy of Agricultural Sciences and reared on tea plants for 4-6 generations. A. fabae was provided by the Institute of Plant Protection, Guizhou Academy of Agricultural Sciences, and reared on 2-weekold faba bean seedlings. The apterous aphids reproduced by cyclical parthenogenesis. The annual seedlings of tea (Qiancha No. 1) were collected from a tea plantation of Meitan County, Guizhou Province. Then, 2-3 tea seedlings were planted in a small pot (length $\times$ width $\times$ height: $10 \mathrm{~cm} \times 8.5 \mathrm{~cm} \times 10 \mathrm{~cm}$ ). Faba beans used as banker plants in the experiment were prepared according to the following procedure. First, faba bean seeds were soaked in water for 5-6 h, and the excess water was then removed. Next, all faba bean seeds were placed in a bamboo basket and moisturized by covering with a wet towel. After $1 / 3$ of the faba bean seeds had sprouted, they were placed in a climate chamber for vernalization for $14 \mathrm{~d}\left(4 \pm 1^{\circ} \mathrm{C}\right.$ and $\mathrm{RH} 70 \pm 5 \%$ in darkness). Faba bean seeds were planted in small pots (three seeds per pot) after vernalization and used for experimentation when the seedlings reached a height of $10-15 \mathrm{~cm}$. All experiments were conducted at $25 \pm 1{ }^{\circ} \mathrm{C}, 70 \pm 5 \%$ relative humidity, and 16:8 h of light (L):dark (D) in an air-conditioned room.

\subsection{Evaluating A. fabae Fitness on Faba Bean and Tea}

Amounts of 5,10, and $15 \mathrm{~A}$. fabae adults were separately introduced into three pots of annual tea seedlings, and $5 \mathrm{~A}$. fabae adults were introduced into a pot of faba bean seedlings. Then, the tea plants and faba bean seedlings infested with $A$. fabae were maintained in separate cages $(30 \mathrm{~cm} \times 30 \mathrm{~cm} \times 30 \mathrm{~cm})$. A. fabae numbers were counted daily until all had died. Each treatment was replicated three times.

\subsection{Evaluating the Initial A. fabae Population to Maintain O. strigicollis}

Five female $A$. fabae adults ( 3 days post-emergence) were released into each of the four 120-mesh insect-proof cages with one pot of faba bean (approx. 10-15 cm tall). Then, five female $O$. strigicollis adults ( 3 days old) were introduced into each of the three cages with $A$. fabae after 24,48 , and $72 \mathrm{~h}$, respectively. Cages without $O$. strigicollis were used as control. The numbers of $A$. fabae were counted daily at 16:00 for 10 days. Each treatment was replicated three times.

\subsection{Evaluating Control Efficacy of Banker Plants on D. minowai}

Four treatments were conducted: (1) In the O. strigicollis-V. faba-A. fabae banker plant system, one pot of $V$. faba and six pots of tea seedlings were placed in a muslin cage (length $\times$ width $\times$ height of $60 \mathrm{~cm} \times 45 \mathrm{~cm} \times 45 \mathrm{~cm}$; the cage size was the same for treatments 1-4). Five $A$. fabae were introduced into the cage for $72 \mathrm{~h}$ before releasing female O. strigicollis adults, and 50 D. minowai were then introduced into the cage after 10 days. (2) For direct release of $O$. strigicollis, five female $O$. strigicollis adults were released into the muslin cage with six pots of tea seedlings, and $50 \mathrm{D}$. minowai were then introduced into the cage after 10 days. (3) For the banker plant system without $O$. strigicollis, five $A$. fabae were released into a cage with one pot of $V$. faba and six pots of tea seedlings, and 50 D. minowai were then introduced into the cage after 10 days. (4) For thrips only, 50 D. minowai were introduced into a cage with six pots of tea seedlings. All mated female O. strigicollis adults 
were used in the experiment at 3 days post-emergence. D. minowai numbers were counted weekly for 4 weeks. Each treatment was replicated four times.

\subsection{Statistical Analyses}

Since the data were not distributed normally, significant differences in the number of $D$. minowai were analyzed using non-parametric Kruskal-Wallis tests followed by Dunn-Bonferroni post hoc pairwise comparisons (SPSS 25.0; IBM Company, Armonk, NY, USA). Figures were drawn using GraphPad Prism 8 (GraphPad Software Inc., San Diego, CA, USA).

\section{Results}

\subsection{Host Specificity of A. fabae}

When $A$. fabae adults were reared on tea seedlings, they all died after 4, 6, and 9 days when the initial numbers of adults were 5,10 and 15 , respectively; by contrast, the number of $A$. fabae reared on faba bean increased steadily after the initial release of five adults and reached about 16 times that of day 1 (Figure 1). These results indicate that $A$. fabae have poor survival on tea plants.

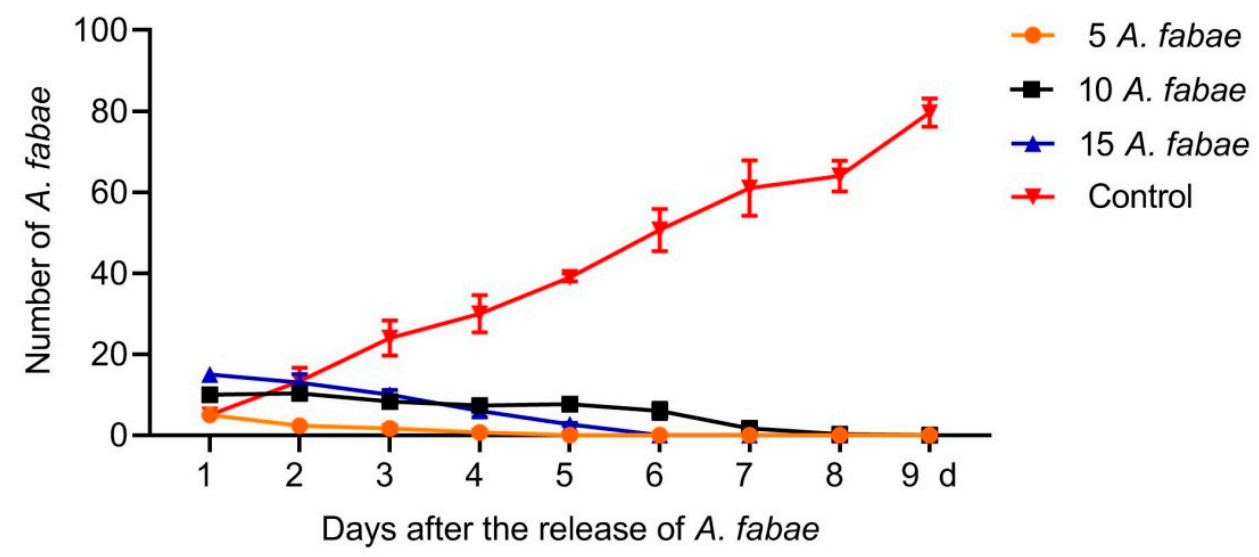

Figure 1. Numbers of Aphis fabae on tea or faba been plants on different days after the initial release of aphid adults. Five, ten, and fifteen $A$. fabae adults were released into each of the three insect cages containing one pot of tea seedlings. Five $A$. fabae adults were reared on three Vicia faba seedlings as a control. Numbers of $A$. fabae were counted daily until all $A$. fabae on tea seedlings died. Data are presented as mean $\pm \mathrm{SEM}$.

\subsection{Initial A. fabae Population to Maintain O. strigicollis}

Five $A$. fabae were released onto faba bean seedlings and allowed to feed and reproduce freely for 24,48 , and $72 \mathrm{~h}$ to obtain different sizes of initial population. The steady increase in aphid number in the treatment without $O$. strigicollis indicates that these plants are a suitable host for the aphid (Figure 2). In the two treatments where the aphids were left to feed and reproduce for 24 and $48 \mathrm{~h}$, the mean numbers of aphids increased to 18 (3.6 times higher than the original) and 32 (6.4 times higher than the original), respectively. However, the numbers of aphids deceased steadily and down to zero at 4 and 6 days after release of the Orius adults, respectively (Figure 2). In the treatment where the aphids were left to feed and reproduce for $72 \mathrm{~h}$, the mean number of aphids increased to 46 (9.2 times higher than the original), and number of aphids declined slowly after the release of Orius adults and remained at around 20 from day 7 onwards (Figure 2). 


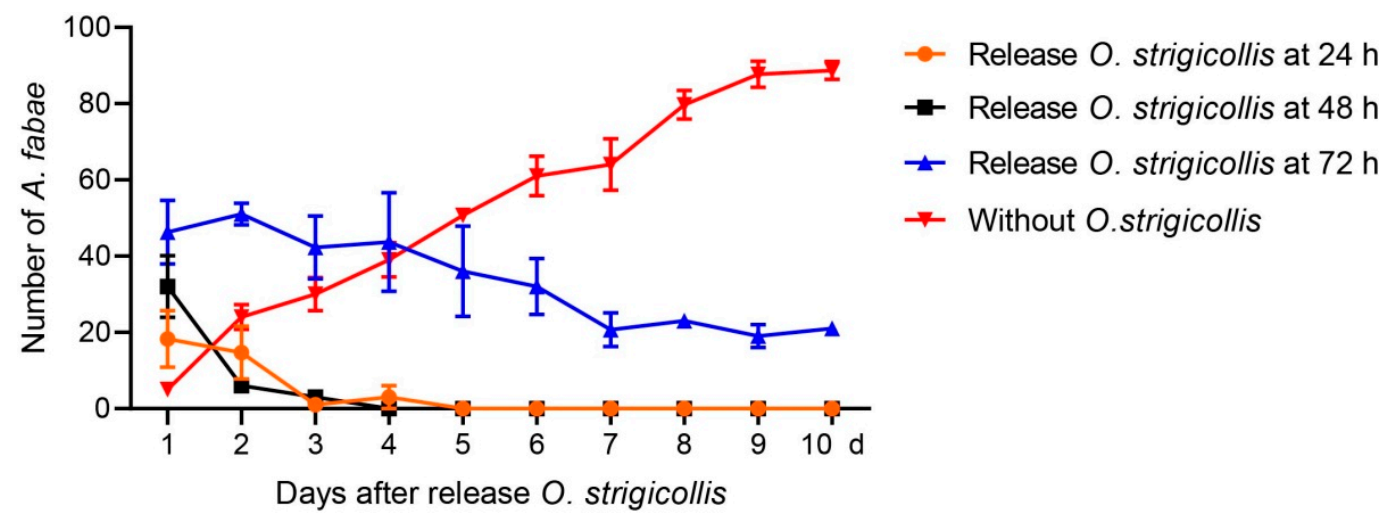

Figure 2. Number of surviving Aphis fabae in different treatments after the release of Orius strigicollis adults. Five Orius adults were introduced when the aphids had been feeding and reproducing on faba bean seedlings for 24,48 , and $72 \mathrm{~h}$, and the treatment of aphids without release of Orius was used as control. Numbers of A. fabae were counted daily for 10 days.

\subsection{Efficacy of Banker Plant System for the Control of D. minowai}

In the $O$. strigicollis- $V$. faba- $A$. fabae banker plant system, $A$. fabae and $O$. strigicollis were pre-released on faba bean seedlings for 10 days prior to the release of $50 \mathrm{D}$. minowai onto the tea seedlings. The results of Kruskal-Wallis testing revealed that there was a significant difference in the number of $D$. minowai among treatments $\left(21 \mathrm{~d}: \chi^{2}=8.609, \mathrm{df}=3, p=0.035\right.$; $28 \mathrm{~d}: \chi^{2}=8.809, \mathrm{df}=3, p=0.032 ; 35 \mathrm{~d}: \chi^{2}=8.597, \mathrm{df}=3, p=0.035 ; 42 \mathrm{~d}: \chi^{2}=9.486, \mathrm{df}=3$, $p=0.023 ; 49 \mathrm{~d}: \chi^{2}=9.336, \mathrm{df}=3, p=0.025$ ) (Figure 3). However, the Dunn-Bonferroni post hoc test indicated the difference between each of the two treatments was not statistically significant from 21 to $35 \mathrm{~d}$. Compared with the banker plant system without $O$. strigicollis and thrips only treatments, the number of $D$. minowai in the treatment of the banker plant system was significantly lower at $42 \mathrm{~d}$ (Figure 3). Moreover, we found that in the treatment of banker plant system, the number of $D$. minowai approached 0 throughout the experiment, which was lower than that of the other three treatments (Figure 3).

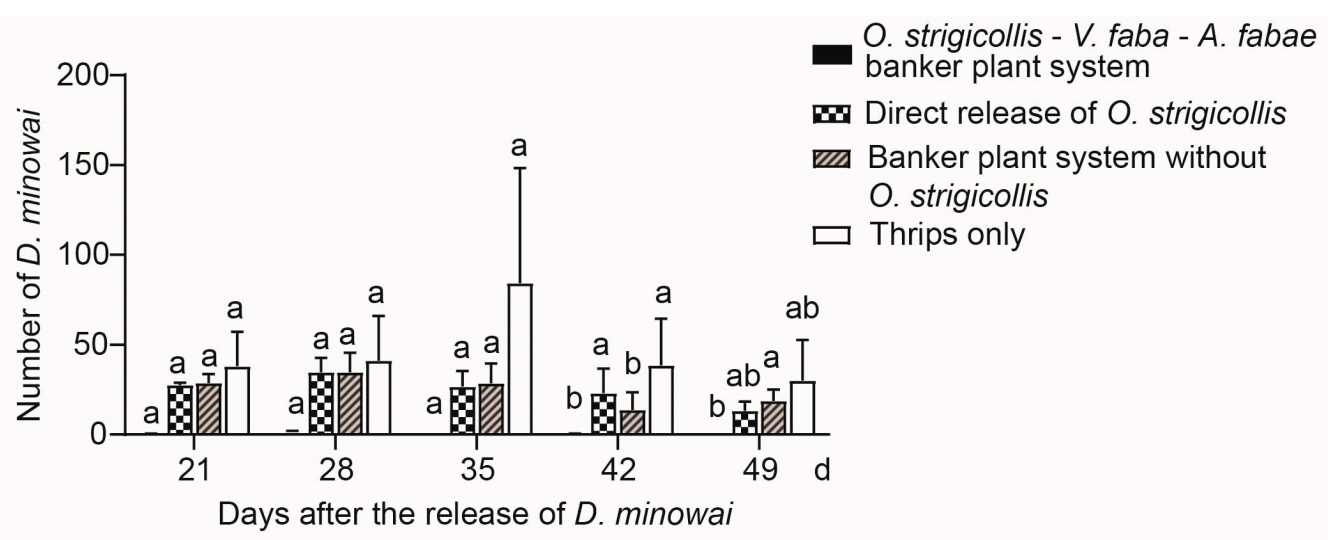

Figure 3. Number of Dendrothrips minowai on tea seedlings in the four treatments: (1) O. strigicollis-V. faba-A. fabae banker plant system, (2) direct release of $O$. strigicollis, (3) banker plant system without $O$. strigicollis, and (4) thrips only. Numbers of $D$. minowai were counted weekly for 4 weeks after releasing. Data are presented as mean \pm SEM. Different letters indicate significant differences among the four treatments separately in each of the dates $(p<0.05)$ calculated using Kruskal-Wallis tests followed by Dunn-Bonferroni tests.

\section{Discussion}

Although the banker plant system has been applied to control pests such as whiteflies, aphids, and thrips, much work is still needed to screen different banker plant components to target different crops and pests. Here, an O. strigicollis-based banker plant system was established for its potential application in the control of the tea pest thrips $D$. minowai. In 
the established system, faba bean is a non-crop host plant for $A$. fabae, which serves as alternative prey to support the beneficial insect $O$. strigicollis.

In a successful banker plant system, alternative preys that are specific to the banker plant are preferable in order to eliminate the risk that the crop becomes infested by the herbivore. A. fabae could only survive for a few days on tea plants but reproduced quickly on faba bean (Figure 1), indicating that $A$. fabae is both a non-pest alternative herbivore for maintaining the predator $O$. strigicollis and not a pest for tea plants. In addition, there are three major advantages to using faba bean as banker plants. First, faba bean is easy to grow in the field and greenhouse and can be heavily fed on by $A$. fabae, which can provide a long-term food source for $O$. strigicollis. Second, faba bean has a high ability to fix nitrogen $(\mathrm{N})$ from the atmosphere and can therefore provide a source of $\mathrm{N}$ for the crop [28]. Third, faba bean may attract other natural enemies, such as Aphidoletes aphidimyza (Diptera: Cecidomyiidae) and Lysiphlebus fabarum (Hymenoptera: Braconidae: Aphidiinae), through provision of $A$. fabae as a food [29,30]. It is possible that faba bean could serve as a banker plant to support multiple natural enemies to target different pests. Moreover, according to our previous laboratory study, O. strigicollis egg production is higher on faba bean than that on Rosa chinensis, Narcissus jonquilla, Capsicum annuum, and Cucumis sativus [31], indicating that faba bean can simultaneously satisfy the reproduction of natural enemy and alternative prey. Moreover, Hansen et al. (1983) used faba bean as a banker plant, providing Megoura viciae (Hemiptera: Aphididae) as alternative food to support $A$. aphidimyza for the control of Myzus persicae in sweet pepper [32]. Faba bean can also supply Megoura japonica (Hemiptera: Aphididae) as alternative food for the support of Coccinella septempunctata (Coleoptera: Coccinellidae) in controlling Aphis gossypii (Hemiptera: Aphididae) (unpublished).

According to a previous study, a long pre-plant release period can significantly increase the abundance of predator Macrolophus pygmaeus (Hemiptera: Miridae) and its efficiency in controlling Bemisia tabaci (Hemiptera: Aleyrodidae) and Tuta absoluta (Lepidoptera: Gelechiidae) on tomato [33]. In this study, an interval of 10 days that was similar to the preplant release period was used. During the 10 days, O. strigicollis only fed on the A. fabae on faba bean, which may have increased the adaptation and initial population of the predator, thus allowing it to successfully establish. Moreover, one of the key factors influencing the establishment of a natural enemy is the amount of prey, so a laboratory experiment was performed to estimate the size of the initial $A$. fabae population required to maintain $O$. strigicollis under conditions without the pest $D$. minowai. The results showed that the number of $A$. fabae reached 46 after $72 \mathrm{~h}$ of reproduction, which could maintain the initial population of five $O$. strigicollis for at least 10 days and allow the number to be maintained at a relatively high level (Figure 2).

Although there was no statistically significant difference, the number of D. minowai in the $O$. strigicollis banker plant system was found to be lower than that when O. strigicollis were directly released throughout the experiment (Figure 3). These results are similar to those reported by Wong and Frank (2011), who established an O. insidiosus-black pearl pepper banker plant system and found that its control efficacy was higher than that of direct $O$. insidiosus release [22]. In this experiment, two treatments without $O$. strigicollis (i.e., the banker plant system without $O$. strigicollis and thrips only) were also evaluated to analyze interactions between plants (faba bean and tea) and alternative prey and pests. These treatments were also used as controls for the two treatments with $O$. strigicollis (i.e., the O. strigicollis $-V$. faba-A. fabae banker plant system and direct release of $O$. strigicollis). The possible reason for the result is that $O$. strigicollis may became pre-established due to the banker plant system providing alternative prey and shelter. However, direct release resulted in reduced survival of $O$. strigicollis, likely due to a lack of food.

The present study was conducted under controlled conditions in a laboratory, which may limit the applicability of the results to the field. However, the results obtained here indicate that this established O. strigicollis banker plant system has great potential for field application. Atakan (2010) showed that Orius will move from overwintering sites, such as weeds to faba beans, when the temperature increases during the period of from March to 
April [26]. According to the previous investigation, O. strigicollis was found on faba bean in March, and tea pests, such as thrips, leafhoppers, and whiteflies, began to appear in tea plantations in April. Therefore, interplanting faba beans in tea plantation in February may attract $O$. strigicollis prior to target pest occurrence. The alternative prey $A$. fabae may play a positive role in the establishment of $O$. strigicollis. While the direct release method requires the purchase and release of a large number of $O$. strigicollis, which is expensive and time-consuming, there is no commercial $O$. strigicollis available. The production of predators from banker plants could reduce the high cost of releasing natural enemies. The effectiveness of the $O$. strigicollis banker plant system in commercial tea plantations needs further study. Additionally, the efficacy of banker plant systems is also affected by factors such as the spatial arrangement, season, release rate, and spreading ability of the natural enemy, all of which require further study.

\section{Conclusions}

The results of this study indicate that it may be possible to use the banker plant system to control D. minowai as well as other tea pests in the field. This strategy may be attractive to growers as it provides a more effective and economical way to control pests than direct the release of $O$. strigicollis.

Author Contributions: Conceptualization, C.-R.Z.; methodology, M.L. and C.-R.Z.; data analysis, M.L. and F.-X.B.; writing-original draft preparation, F.-X.B.; writing—review and editing, C.-R.Z., F.-X.B., X.-L.S., T.-T.M., S.-L.L., X.-Y.Z. and J.-R.Z.; funding acquisition, C.-R.Z. All authors have read and agreed to the published version of the manuscript.

Funding: This research was financially supported by the National Natural Science Foundation of China (31660542) and the Natural Science of Foundation of Guizhou Province [2020] 1Z024.

Institutional Review Board Statement: Not applicable.

Data Availability Statement: The data presented in this study are available in article.

Acknowledgments: We thank Qian-Jun Ran, Ye Fu, and Jin-Hong Huang for planting tea seedlings, raising insects, and managing the laboratory. We thank Shu-Sheng Liu for the comments of this manuscript.

Conflicts of Interest: The authors declare no conflict of interest.

\section{References}

1. Wang, Z.; Mound, L.A.; Tong, X.; Tong, X. Character state variation within Dendrothrips (Thysanoptera: Thripidae) with a revision of the species from China. Zootaxa 2019, 4590, 231-248. [CrossRef] [PubMed]

2. Lyu, Z.Y.; Zhi, J.R.; Zhou, Y.F.; Meng, Z.H.; Yue, W.B. Genetic diversity and origin of Dendrothrips minowai (Thysanoptera: Thripidae) in Guizhou, China. J. Asia Pac. Entomol. 2016, 19, 1035-1042. [CrossRef]

3. Bian, L.; Yang, P.X.; Yao, Y.J.; Luo, Z.X.; Cai, X.M.; Chen, Z.M. Effect of trap color, height, and orientation on the capture of yellow and stick tea thrips (Thysanoptera: Thripidae) and nontarget insects in tea gardens. J. Econ. Entomol. 2016, 109, 1241-1248. [CrossRef]

4. Li, X.Y.; Qi, P.Y.; Zhang, Q.P.; Zhang, R.F.; Chen, Z.; Jin, L.H.; Song, B.A. Introduction of two predators to control Dendrothrips minowai (Thysanoptera: Thripidae) in tea (Camellia sinensis) plantations in China. Biocontrol Sci. Technol. 2020, 30, $431-441$. [CrossRef]

5. Keçeci, M.; Gürkan, M.O. Biological control of western flower thrips, Frankliniella occidentalis with Orius species in eggplant greenhouses in Turkey. Turk. Entomol. Derg-Tu 2013, 37, 467-476.

6. Maria, V.A.; Ioana, G.; Ramona, S.; Alin, C.; Levente, M.; Veaceslav, M. Biological control of Odontothrips loti (Hal.) with anthocorid predators Orius minutus (L.) and Orius niger (Wolf.). J. Biotechnol. 2016, 231, S88. [CrossRef]

7. Rahman, M.A.; Sarker, S.; Ham, E.; Lee, J.S.; Lim, U.T. Development and fecundity of Orius minutus (Hemiptera: Anthocoridae) and O. laevigatus reared on Tetranychus urticae (Acari: Tetranychidae). J. Econ. Entomol. 2020, 113, 1735-1740. [CrossRef]

8. Montoro, M.; De Fine Licht, H.H.; Sigsgaard, L. Nutritional quality of Drosophila melanogaster as factitious prey for rearing the predatory bug Orius majusculus. Insect Sci. 2021, 28, 191-202. [CrossRef] [PubMed]

9. Herrick, N.J.; Cloyd, R.A. Direct and indirect effects of pesticides on the insidious flower bug (Hemiptera: Anthocoridae) under laboratory conditions. J. Econ. Entomol. 2017, 110, 931-940. [CrossRef]

10. Jung, S.; Yamada, K.; Lee, S. Annotated catalog, biological notes and diagnoses of the flower bugs (Heteroptera: Anthocoridae sensu lato) in the Korean Peninsula. J. Asia Pac. Entomol. 2013, 16, 421-427. [CrossRef] 
11. Rehman, S.U.; Zhou, X.; Ali, S.; Asim Rasheed, M.; Islam, Y.; Hafeez, M.; Aamir Sohail, M.; Khurram, H. Predatory functional response and fitness parameters of Orius strigicollis Poppius when fed Bemisia tabaci and Trialeurodes vaporariorum as determined by age-stage, two-sex life table. PeerJ 2020, 8, e9540. [CrossRef] [PubMed]

12. Tuan, S.J.; Yang, C.M.; Chung, Y.T.; Lai, W.H.; Ding, H.Y.; Saska, P.; Peng, S.C. Comparison of demographic parameters and predation rates of Orius strigicollis (Hemiptera: Anthocoridae) fed on eggs of Tetranychus urticae (Acari: Tetranychidae) and Cadra cautella (Lepidoptera: Pyralidae). J. Econ. Entomol. 2016, 109, 1529-1538. [CrossRef] [PubMed]

13. Shibao, M.; Tanaka, H. Control of the western flower thrips, Frankliniella occidentalis (Pergande) on greenhouse eggplant by releasing of Orius strigicollis (Poppius). Ann. Rep. Kansai Plant Protect. Soc. 2000, 42, 27-30. [CrossRef]

14. Jiang, Y.L.; Wu, Y.Q.; Duan, Y.; Gao, X.G. Control efficiencies of releasing Orius sauteri (Heteroptera:Anthocoridae) on some pests in greenhouse pepper. Chin. J. Biol. Control 2011, 27, 414-417.

15. Manandhar, R.; Wright, M.G. Enhancing biological control of corn earworm, Helicoverpa zea and thrips through habitat management and inundative release of Trichogramma pretiosum in corn cropping systems. Biol. Control 2015, 89, 84-90. [CrossRef]

16. Sarra, B.; Alberto, U.; Meritxell, P.H. Combined use of predatory mirids with Amblyseius swirskii (Acari: Phytoseiidae) to enhance pest management in sweet pepper. J. Econ. Entomol. 2018, 111, 1112-1120.

17. Frank, S.D. Biological control of arthropod pests using banker plant systems: Past progress and future directions. Biol. Control 2010, 52, 8-16. [CrossRef]

18. Zheng, X.; Lu, Y.; Zhu, P.; Zhang, F.; Tian, J.; Xu, H.; Chen, G.; Nansen, C.; Lu, Z. Use of banker plant system for sustainable management of the most important insect pest in rice fields in China. Sci. Rep. 2017, 7, 45581. [CrossRef] [PubMed]

19. Huang, N.; Enkegaard, A.; Osborne, L.S.; Ramakers, P.M.J.; Messelink, G.J.; Pijnakker, J.; Murphy, G. The banker plant method in biological control. CRC Crit. Rev. Plant Sci. 2011, 30, 259-278. [CrossRef]

20. Payton Miller, T.L.; Rebek, E.J. Banker plants for aphid biological control in greenhouses. J. Integr. Pest Manag. 2018, 9, 1-8. [CrossRef]

21. Wong, S.K.; Frank, S.D. Influence of banker plants and spiders on biological control by Orius insidiosus (Heteroptera: Anthocoridae). Biol. Control 2012, 63, 181-187. [CrossRef]

22. Wong, S.K.; Frank, S.D. Pollen increases fitness and abundance of Orius insidiosus Say (Heteroptera: Anthocoridae) on banker plants. Biol. Control 2013, 64, 45-50. [CrossRef]

23. Zhao, J.; Guo, X.; Tan, X.; Desneux, N.; Zappala, L.; Zhang, F.; Wang, S. Using Calendula officinalis as a floral resource to enhance aphid and thrips suppression by the flower bug Orius sauteri (Hemiptera: Anthocoridae). Pest Manag. Sci. 2007, 73, 515-520. [CrossRef]

24. Rashedi, A.; Rajabpour, A.; Rasekh, A.; Zandi-Sohani, N. Interactions between host plant, Aphis fabae, and its natural enemies, Orius albidipennis and Lysiphlebus fabarum in a tritrophic system. J. Asia Pac. Entomol. 2019, 22, 847-852. [CrossRef]

25. Zheng, S.S.; Zhi, J.R.; Zhang, C.R.; Liu, F.J. Studies on Orius silimis development and reproduction with broad bean aphid as prey. J. Henan Agric. Sci. 2009, 12, 88-91.

26. Atakan, E. Influence of weedy field margins on abundance patterns of the predatory bugs Orius spp. and their prey, the western flower thrips (Frankliniella occidentalis), on faba bean. Phytoparasitica 2010, 38, 313-325. [CrossRef]

27. Zhang, J.; Zhi, J.R.; Yang, C.Y.; Li, S.X. Investigation and identification of farmland Orius Wolff in Guizhou province. J. Mt. Agric. Biol. 2015, 1, 36-40.

28. Köpke, U.; Nemecek, T. Ecological services of faba bean. Field Crops Res. 2010, 115, 217-233. [CrossRef]

29. Havelka, J.; Růžička, Z. Selection of aphid species by ovipositing females and effects of larval food on the development and fecundity in Aphidoletes aphidimyza (Rondani) (Diptera, Cecidomyiidae). Zeitschr. Angew. Entomol. 1984, 98, 432-437. [CrossRef]

30. Völkl, W.; Stechmann, D.H. Parasitism of the black bean aphid (Aphis fabae) by Lysiphlebus fabarum (Hym., Aphidiidae): The influence of host plant and habitat. J. Appl. Entomol. 1998, 122, 201-206. [CrossRef]

31. Zhang, C.R.; Ban, F.X.; Shang, X.L.; Liu, S.L.; Mao, T.T.; Zhang, X.Y.; Liu, M.; Guo, J.; Sun, Y.H. Evaluation of five plant species for their suitability as banker plant for Orius similis (Zheng). J. Environ. Entomol. 2021, in press.

32. Hansen, L.S. Introduction of Aphidoletes aphidimyza (Rond.) (Diptera: Cecidomyiidae) from an open rearing unit for the control of aphids in glasshouses. Bull. SROP 1983, 6, 146-150.

33. Sanchez, J.A.; López-Gallego, E.; Pérez-Marcos, M.; Perera-Fernández, L. The effect of banker plants and pre-plant release on the establishment and pest control of Macrolophus pygmaeus in tomato greenhouses. J. Pest. Sci. 2020. [CrossRef] 